\title{
Farklı Yaşlardaki Anason (Pimpinella anisum L.) Tohumlarının Çimlenmesine Gibberellik Asitin (GA3) Etkisi
}

\author{
Mortaza HAJYZADEH $^{1} \quad$ Mehmet Uğur YILDIRIM $^{1} \quad$ İsmail KARAGÖZ $^{1} \quad$ Ercüment O. SARIHAN ${ }^{1}$ \\ Khalid Mahmood KHAWAR ${ }^{2}$ \\ ${ }^{1}$ Uşak Üniversitesi, Ziraat ve Doğa Bilimleri Fakültesi, Tarla Bitkileri Bölümü, UŞAK. \\ ${ }^{2}$ Ankara Üniversitesi, Ziraat Fakültesi, Tarla Bitkileri Bölümü, ANKARA \\ $\triangle$ : m.hajyzadeh@gmail.com
}

Geliş (Received): 04.11.2017

Kabul (Accepted): 15.12.2017

\begin{abstract}
ÖZET: Bu çalışma; farklı gibberellik asit (GA3) dozlarının, farklı tohum yaşlarındaki anason (Pimpinella anisum L.) tohumlarının çimlenmesine olan etkisini belirlemek üzere yapılmıştır. Çalışmada; Burdur yöresinden; anason ekimi yapılan yerlerden temin edilen tohumlar materyal olarak kullanılmıştır. Yörede her yıl ekimi yapılan anason bitkisinin tohumları 4 y1l boyunca dört ayrı yaşta (1, 2, 3 ve 4 yaşındaki) olmak üzere temin edilmiş ve materyal olarak kullanılmıştır. Denemede; 4 farklı yaştaki anason tohumlarına 24 saat süreyle 50, 100, 200, $400 \mathrm{ve} 800 \mathrm{mg} / 1$ GA3 uygulanmış, kontrol uygulamasında ise sadece su kullanılmıştır. Daha sonra; kâğıt havlu ile kurutulan tohumlar, petri kutularında, kağıt arasında 25 oC'de oda sıcaklığında çimlendirmeye alınmıştır. Deneme 4 tekrarlamalı olarak tesadüf parselleri deneme desenine göre kurulup yürütülmüştür. Her uygulamada 100'er adet tohum kullanılmıştır. Sayımlar ISTA kurallarına göre 7. ve 21. günde yapılmıştır. Tohum yaşlarına göre çimlenme yüzdesi \% 36.3 ile 69.0 arasında değişmiş ve 4 yaşındaki tohumlarda çimlenme oranı en düşük olarak bulunmuştur. Hormon dozlarına göre çimlenme \% 32.3 ile 58.3 arasında değişmiş, en düşük çimlenme $800 \mathrm{mg} / \mathrm{l}$ hormon dozundan elde edilmiştir. Tohum yaşı ve hormon dozları birlikte değerlendirildiğinde 2 yaşındaki tohumlara uygulanan $100 \mathrm{mg} / \mathrm{l}$ hormon dozunda en yüksek çimlenme (\%83.5) elde edilmiştir.
\end{abstract}

Anahtar Kelimeler: Anason, Çimlenme, Hormon, Gibberellik Asit, Tohum Yaşı

\section{Effects of Gibberellic Acid (GA3) on The Germination Rate of Anise (Pimpinella Anisum L.) Seeds in Different Ages}

\begin{abstract}
The study was conducted to determine different (GA3) doses on germination of anise (Pimpinella anisum L.) seeds at different age. In the study; the anise seeds obtained from aniseed sowing regions in Burdur province; were used as material. Four different seed ages of anise (1, 2, 3 and 4 years old) were used as material. Remaining anise seeds were stored and used for next season sowing. In the study 50, 100, 200, 400 and $800 \mathrm{mg} / 1$ GA3 and water (control) were applied to each group of 4 different aged anise seeds for 24 hours. Later; the seeds were dried with paper towels and sandwiched between towel papers in petri dishes and cultured at $25 \mathrm{oC}$. The experimental design was completely randomized design with four replications. In each treatment 100 seeds were used. The germination counts were made on the 7 th and 21 st days according to the ISTA rules. The percentage of germination varied between 36.3 and $69.0 \%$ among different groups of seed ages. Germination was the lowest on 4 year old seeds. Germination by hormone doses ranged from $32.3 \%$ to $58.3 \%$. The lowest germination was obtained from $800 \mathrm{mg} / \mathrm{l} \mathrm{GA} 3$ dose. When the seed age and hormone doses were evaluated together, the highest germination rate $(83.5 \%)$ was obtained from treatment of $100 \mathrm{mg} / \mathrm{l} \mathrm{GA} 3$ on 2 year's old seeds

Key words: Anise, Germination, Hormone, Gibberellic Acid, Seed Age
\end{abstract}

\section{GİRIŞ}

Türkiye, değişik iklim özellikleri ve uygun coğrafi yapısından dolayı tıbbi ve aromatik türler bakımından zengin bir biyoçeşitliliğe sahiptir. Türkiye sahip olduğu ekolojik koşullarda tıbbi ve aromatik bitkilerin tarımı ve yetiştiriciliği açısından önemli bir potansiyel ortaya koymaktadır (Durmuş ve Yiğit, 1998). Türkiye'de her geçen gün kullanım alanları artan, tıbbi ve aromatik bitkilerin gıda, drog, ilaç, sanayi başta olmak üzere diğer bir çok sektörde kullanımları giderek yaygınlaşmakta ve artmaktadır. Kültürü yapılan tıbbi ve aromatik bitkiler içerisinde kekik, gül, haşhaş, anason, çemen, nane, çörekotu vb. türler önemli bir yer tutmaktadır. Geleneksel üretim deseninde kullanılan bitkilere alternatif olarak, yetiştiriciliği gelişen ürünler içerisinde yer alan anason bitkisinin, tohum ve uçucu yă̆ ihracatında önemli bir yeri vardır. Anason (Pimpinella anisum L.), Apiaceae familyasına ait bir bitki olup, yaygın olarak Dünya'da İtalyan, İspanyol, Alman, Rusya ve Türk Anasonu olarak (Çeşme ve Burdur) tanınmaktadır (Ceylan, 1996). Tohumlarında \%1-6 oranında uçucu yağ bulunmaktadır. Bu yağın \%75-80'i, bu yağa kendine özgü kokusunu veren, transanetolden oluşmaktadır (Kaya, 1990; Akgül, 1993). Bitkideki bu uçucu yağ; çoğunlukla tıbbi olarak; antispazmodik, sindirim uyarıcı, balgam söktürücü, boğaz ağrıları giderici, öksürük kesici ve diş iltihaplarını kurutucu, antifungal ve antidepresan şeklinde kullanılmaktadır. Bunun yanı sıra kozmetik sanayinde, sabun ve deterjanlar yapımında ayrıca gida sanayinde de kullanılmaktadır (Başer, 1997; Tunçtürk ve Yıldırım, 2006; Meena ve ark., 2012). Türkiye'de yapılan anason 
üretiminin \%75-80 kadarı başta ABD, Brezilya, Hollanda, Almanya, Fransa, İtalya, İspanya ve Yunanistan gibi ülkelere ihraç edilmektedir. ABD, anason ihtiyacının \%50'den fazlasını Türkiye'den karşılamaktadır (Baydar, 2016). Türkiye'de toplam 15.200 ha alanda anason yetiştirilmekte ve ortalama 10.046 ton ürün elde edilmektedir. Denizli, Burdur, Antalya, Muğla, Isparta ve İzmir illeri en fazla üretimin gerçekleştirildiği illerdir (Kara, 2015). Son yıllarda; Türkiye'de anason ekiliş alanlarında yıllara göre (20102015) belirgin bir azalış gözlenmektedir. $\mathrm{Bu}$ düşüşün sebeplerinin başında ekimden sonraki süreçte yaşanan çıkış sorunu gelmektedir. Bitki ilk gelişme döneminde zayıf gelişmekte ve yabancı otlarla rekabette sorun yaşanmaktadır.

Türkiye'de tescilli tek Gölhisar çeşiti bulunmaktadır. Ancak bu çeşidin de sertifikalı tohumluğunun kullanımı oldukça azdır. Zira bu çeşit oldukça eski bir çeşit olup yeni ve verimli çeşitlerin de tescilinin yapılmamış olması çiftçiyi bu çeşidin içerisinden kendi tohumluğunu ayırarak üretim yapmaya itmektedir. $\mathrm{Bu}$ da kaliteli ve olgun tohumların tohumluk olarak kullanılmasında önemli bir sorun olarak karşımıza çıkmaktadır. Çiftçinin elindeki tohumların yaşı ve olgunluğu yetiştiricilikte önem arz etmektedir. Kullanılan tohumluğun yaşı arttıkça çimlenme oranlarında ciddi düşüşler yaşanmaktadır. Ancak; yaşlı ve tam olgunlaşmamış tohumların karışık olduğu tohumluklarda bir takım uygulamalar ile çimlenme oranını arttırılabilmektedir. Gibberellik asit $\left(\mathrm{GA}_{3}\right)$ muamelesi bu uygulamalar arasında başta gelmektedir. Çimlenme sürecinde çoklu düzenleyici etkisi ile önemli bir rol üstlenmektedir (Ritchie ve Gilroy, 1998; Fincher, 1989). Ancak tohum çimlenmesindeki etkisinin tüm kültür bitkilerinde aynı olmadığı da bilinmektedir (Bell ve ark., 1995). GA3'ün farklı bitki türlerinde tohum çimlenmesi üzerine etkilerini belirlemek amacıyla yapılan çalışmaların sonuçlarına göre, bazı türlerde çok etkili olduğu buna karşın bazı türlerde her hangi bir etkisinin olmadığı rapor edilmiştir (Gulzar ve Khan, 2002; Liopa-Tsakalidi ve ark., 2011). Ancak tıbbi ve aromatik bitkilerde $\mathrm{GA}_{3}$ 'ün çimlenme üzerindeki fiziyolojik etkisi ve performansı hakkında nispeten az bilgi bulunmaktadır. Bu çalışma ile farklı yaşlardaki anason tohumlarında, farklı $\mathrm{GA}_{3}$ doz uygulanmasının çimlenme üzerindeki etkisi araştırılmıştır.

\section{MATERYAL ve METOT}

$\mathrm{Bu}$ çalışma; farklı gibberellik asit $\left(\mathrm{GA}_{3}\right)$ dozlarının farklı tohum yaşlarındaki anason bitkisi (Pimpinella anisum L.) tohumlarının çimlenmesine olan etkisini belirlemek üzere yapılmıştır. Çalışma 2016 yılında laboratuvar çalışması olarak Uşak Üniversitesi Ziraat ve Doğa Bilimleri Fakültesi Araştırma ve Uygulama Laboratuvarı ve iklim odalarında kurulup yürütülmüştür. Çalışmada bitki materyali olarak; Burdur bölgesinde yetiştiriciliği yapılan ve bir sonraki yıl anason üretimi için kullanılmak üzere ayrılan tohumlardan 2013, 2014, 2015 ve 2016 yillarında alınan tohumlar kullanılmıştır. Deneme anına kadar bu tohumlar oda sicaklığında $\left(25^{\circ} \mathrm{C}\right.$ sıcaklıkta), kese kâğıdı içerisinde saklanmıştır. 2013-2016 yılları arasında hasadı yapılmış kalite ölçütlerine uygun ve bir sonraki y1lda tohumluk olarak ekilmesi tercih edilen anason tohumları seçilmiştir. Denemede; Gibberellik asidin farklı dozlar1 (kontrol, 50, 100, 200, 400 ve $800 \mathrm{mg} / 1$ $\left.\mathrm{GA}_{3}\right) 4$ farklı yaştaki anason tohumlarına uygulanmıştır. Kontrol gruplarında ise sadece su uygulaması yapılmıştır. Uygulamalar steril cam petriler içerisinde yapılmıştır. Her uygulama dozu için hazırlanan çözeltilerden $10 \mathrm{ml}$ alınarak petri kutuları içerisine konulmuş ve tohumlar bu çözelti içerisine daldırılarak 24 saat süreyle $25^{\circ} \mathrm{C}$ 'de (oda sıcaklığında) bu çözelti içerisinde bekletilmiştir. Sonrasında çözeltiden çıkartılan tohumlar kurutma kağıtları arasında çimlendirilmiştir. Deneme 4 tekrarlamalı olarak tesadüf parselleri deneme desenine göre kurulup yürütülmüştür. Her uygulamada 100 'er adet tohum kullanılmıştır. Toplam ( 4 tohum yaşı $\mathrm{x} 6$ hormon dozu ve 4 tekerrür $=$ 96 uygulama) 9600 adet tohum ile çimlendirme çalışması yürütülmüştür. Düzenli olarak petri kutularının nemleri kontrol edilerek 21 gün süreyle çalışma sürdürülmüştür. Sayımlar ISTA kurallarına göre yapılmış olup; ilk sayımlar 7. günde ve son sayımlar 21. günde yapılmıştır. İlk sayım çimlenme oranı (\%), son sayım çimlenme oranı (\%) ve çimlenen tohumlarda kökçük uzunluğu (cm) gibi karakterlerde ölçümler yapılmıştır. Ölçülen karakterlere ilişkin ortalama değerler ve bunlara ait varyans analizleri SPSS istatistiki programında yapılmış ve ortalamalar arasındaki farklar Duncan testi ile belirlenmiştir.

\section{BULGULAR}

$\mathrm{Bu}$ çalışmada anason bitkisinin farklı yaşlardaki tohumlarına; uygulanan farklı dozlardaki gibberellik asitin $\left(\mathrm{GA}_{3}\right)$ etkileri tespit edilmiştir. Denemede ölçümü gerçekleştirilen; ilk çimlenme ve son çimlenme değerleri ile kökçük uzunluğu değerlerine ait bulgular aşağıda sunulmuştur.

\section{Ilk Sayım Çimlenme ve Son Sayım Çimlenme Oranlart (\%):}

Tohum yaşlarına ve uygulanan hormon dozlarına göre elde edilen ortalama değerler ile hormon dozu $\mathrm{x}$ tohum yaşı interaksiyonuna ait ortalama değerler ve arasındaki farklar Çizelge 1'de verilmiştir. İlk sayım ve son sayım değerlerine göre hormon dozu x tohum yaşı interaksiyonu ortalama değerleri arasındaki farklar 0.01 seviyesinde önemli bulunmuştur.

İlk çimlenme değerlerine göre tohum yaşlarında ortalama en yüksek çimlenme $\% 26.3$ ile 2 yaşındaki tohumlardan ve en düşük \%13.1 ile 4 yaşındaki tohumlardan elde edilmiştir. Hormon dozları arasında ise ortalama en yüksek çimlenme $200 \mathrm{mg} / \mathrm{l} \mathrm{GA}_{3}$ dozunda \% 24 olurken, en düşük $800 \mathrm{mg} / \mathrm{l} \mathrm{GA}_{3}$ dozunda \% 13.8 olarak gerçekleşmiştir.

Hormon dozu x tohum yaşı interaksiyonunda ise en yüksek çimlenme oran $\% 35$ ile $200 \mathrm{mg} / \mathrm{l} \mathrm{GA}_{3}$ dozunun uygulandığı 2 yaşındaki tohumlardan elde edilmiştir. En düşük ise $400 \mathrm{mg} / \mathrm{l}$ hormon uygulanan 4 yaşındaki tohumlardan \%10.25 elde edilmiştir (Çizelge1). 
Son sayım değerlerine göre tohum yaşları bakımından ortalama en yüksek çimlenme \%69.0 ile 2 . yaşındaki tohumlardan; en düşük \%36.3 ile 4 yaşındaki tohumlardan elde edilmiştir. Hormon dozları bakımından ise ortalama en yüksek çimlenme 50 ve 200 $\mathrm{mg} / \mathrm{l} \mathrm{GA} \mathrm{A}_{3}$ dozlarinda sirasiyla \%58.3-58.1 olurken; en düşük $\quad 800 \quad \mathrm{mg} / 1 \quad \mathrm{GA}_{3}$ dozunda $\% \quad \begin{array}{llll} & 32.3 & \text { olarak }\end{array}$ gerçekleşmiştir.
Hormon dozu $\mathrm{x}$ tohum yaşı interaksiyonunda ise en yüksek çimlenme oranı $\% 83.5$ ile $100 \mathrm{mg} / \mathrm{l} \mathrm{GA}_{3}$ dozunun uygulandığı 2 . yaşındaki tohumlardan elde edilmiştir. En düşük ise $400 \mathrm{mg} / 1$ hormon uygulanan, 4 yaşındaki tohumlardan \%26.0 elde edilmiştir (Çizelge 1)

Çizelge 1. İlk sayım ve son sayım çimlenme oranları (\%) ve bu değerlere ilişkin Duncan grupları

\begin{tabular}{|c|c|c|c|c|c|c|c|c|c|c|}
\hline \multirow{3}{*}{$\begin{array}{c}\mathrm{GA}_{3} \\
\text { dozlar1 }\end{array}$} & \multicolumn{5}{|c|}{ İlk sayım (7 gün) } & \multicolumn{5}{|c|}{ Son sayım (21.gün) } \\
\hline & \multicolumn{4}{|c|}{ Tohum yaşı (yıl) } & & \multicolumn{4}{|c|}{ Tohum yaşı (yıl) } & \multirow[b]{2}{*}{ Ort** } \\
\hline & 1 & 2 & 3 & 4 & Ort $* *$ & 1 & 2 & 3 & 4 & \\
\hline Kontrol & $14.0 \mathrm{jkl}$ & 24.0def & $22.25 \mathrm{fg}$ & $13.25 \mathrm{klm}$ & $18.4 \mathrm{~b}$ & $44.5 \mathrm{gh} 1$ & $50.5 \mathrm{ef}$ & $55.0 \mathrm{~d}$ & $41.81 \mathrm{j}$ & $47.9 \mathrm{c}$ \\
\hline 50 & $20.0 \mathrm{~h}$ & $24.5 \mathrm{de}$ & $19.5 \mathrm{~h}$ & $13.5 \mathrm{klm}$ & $19.4 \mathrm{~b}$ & 48.0efg & $74.5 b$ & $62.3 c$ & $48.3 \mathrm{efg}$ & $58.3 \mathrm{a}$ \\
\hline 100 & $19.75 \mathrm{~h}$ & $26.0 \mathrm{~d}$ & $19.25 \mathrm{~h}$ & $13.25 \mathrm{klm}$ & $19.6 \mathrm{~b}$ & 46.3gh & $83.5 \mathrm{a}$ & $57.8 \mathrm{~d}$ & $38.5 \mathrm{jk}$ & $56.5 b$ \\
\hline 200 & $29.25 \mathrm{c}$ & $35.0 \mathrm{a}$ & $14.75 \mathrm{j}$ & 17.01 & $24.0 \mathrm{a}$ & $62.5 \mathrm{c}$ & $81.5 \mathrm{a}$ & $51.0 \mathrm{e}$ & $37.3 \mathrm{k}$ & $58.1 \mathrm{a}$ \\
\hline 400 & $15.75 \mathrm{ij}$ & $31.5 b$ & $15.01 \mathrm{jk}$ & $10.25 \mathrm{~m}$ & $18.1 \mathrm{~b}$ & $41.51 \mathrm{j}$ & $82.5 \mathrm{a}$ & $55.5 \mathrm{~d}$ & $26.0 \mathrm{~m}$ & $51.4 \mathrm{~b}$ \\
\hline 800 & $14.5 \mathrm{jk}$ & 16.751 & $12.51 \mathrm{~m}$ & $11.5 \mathrm{~m}$ & $13.8 \mathrm{c}$ & 31.31 & 41.3 & 30.31 & $26.3 \mathrm{~m}$ & $32.3 \mathrm{~d}$ \\
\hline Ort $* *$ & $18.9 \mathrm{~b}$ & $26.3 a$ & $17.2 \mathrm{c}$ & $13.1 \mathrm{~d}$ & & $45.7 c$ & $69.0 \mathrm{a}$ & $52.0 \mathrm{~b}$ & $36.3 \mathrm{~d}$ & \\
\hline
\end{tabular}

İlk sayım (7.gün) için; Tohum yaşı x Hormon Dozu interaksiyonu: \pm : 2.168; Son sayım (21. gün)

için: interaksiyon \pm : 3.715 , **ortalama değerleri arasındaki farklar 0.01 seviyesinde önemli bulunmuştur

Çizelge 2. Kökçük uzunluğu (cm) ortalama değerleri ve bu değerlere ilişkin Duncan grupları

\begin{tabular}{|c|c|c|c|c|c|}
\hline \multirow{3}{*}{$\mathrm{GA}_{3}$ dozlar1 } & \multicolumn{4}{|c|}{ Kökçük uzunluğu (cm) } & \multirow{3}{*}{ Ort $* *$} \\
\hline & \multicolumn{4}{|c|}{ Tohum yaşı (yıl) } & \\
\hline & 1 & 2 & 3 & 4 & \\
\hline Kontrol & $2.56 \mathrm{~g}$ & $3.85 \mathrm{e}$ & $2.69 \mathrm{~g}$ & $1.58 \mathrm{~h}$ & $2.7 \mathrm{e}$ \\
\hline 50 & $3.57 \mathrm{e}$ & $6.93 a$ & $6.3 \mathrm{~b}$ & $3.87 \mathrm{e}$ & $5.2 \mathrm{a}$ \\
\hline 100 & $3.4 \mathrm{f}$ & $6.38 \mathrm{~b}$ & $5.82 \mathrm{c}$ & $3.26 \mathrm{f}$ & $4.7 \mathrm{~b}$ \\
\hline 200 & $5.65 \mathrm{c}$ & $4.84 \mathrm{~d}$ & $4.39 \mathrm{~d}$ & $1.7 \mathrm{~h}$ & $4.1 \mathrm{c}$ \\
\hline 400 & $2.56 \mathrm{~g}$ & $4.69 \mathrm{~d}$ & $4.62 d$ & $1.55 \mathrm{~h}$ & $3.4 d$ \\
\hline 800 & $2.6 \mathrm{~g}$ & $2.71 \mathrm{~g}$ & $1.95 \mathrm{~h}$ & $1.73 \mathrm{~h}$ & $2.3 \mathrm{f}$ \\
\hline Ort** & $3.4 \mathrm{c}$ & $4.9 \mathrm{a}$ & $4.3 \mathrm{~b}$ & $2.3 \mathrm{~d}$ & \\
\hline
\end{tabular}

Kökçük uzunluğu (7.gün) için; hormon dozu x tohum yaşı interaksiyonu: \pm : 0.455

**ortalama değerleri arasındaki farklar 0.01 seviyesinde önemli bulunmuştur

\section{Kökçük Uzunluğu (cm)}

Kökçük uzunluğu karakterine ilişkin yapılan istatistiki analize göre; tohum yaşları, hormon dozları ortalama değerleri ile hormon dozu $\mathrm{x}$ tohum yaşı interaksiyonu değerleri arasındaki farklar 0.01 seviyesinde önemli bulunmuştur.

Tohum yaşları bakımından ortalama en yüksek kökçük uzunluğu $4.9 \mathrm{~cm}$ ile 2. yaşındaki tohumlardan; en düşük $2.3 \mathrm{~cm}$ ile 4 yaşındaki tohumlardan elde edilmiștir. Hormon dozları bakımından ortalama en yüksek kökçük uzunluğu $50 \mathrm{mg} / \mathrm{l} \mathrm{GA}_{3}$ dozunda $5.2 \mathrm{~cm}$ olurken; en düșük $800 \mathrm{mg} / \mathrm{l} \mathrm{GA}_{3}$ dozunda $2.3 \mathrm{~cm}$ olarak gerçekleşmiştir.

Hormon dozu $\mathrm{x}$ tohum yaşı interaksiyonunda ise en yüksek kökçük uzunluğu $6.93 \mathrm{~cm}$ ile $50 \mathrm{mg} / 1 \mathrm{GA}_{3}$ dozunun uygulandığı. 2 yaşındaki tohumlardan elde edilmiştir. En düşük ise $1.55 \mathrm{~cm}$ ile $400 \mathrm{mg} / \mathrm{l}$ hormon dozunun uygulandığı, 4 yaşındaki tohumlardan elde edilmiştir (Çizelge 2). Düşük dozlarda uygulanan hormonların kökçük gelişimini genel anlamda arttırdığ 1 gözlenmiştir.

\section{TARTISMA}

$\mathrm{Bu}$ çalışmada farklı yaşlardaki anason tohumlarının çimlenmesi üzerine bitki büyüme düzenleyicisi $\mathrm{GA}_{3}$ ün etkisi incelenmiştir. $\mathrm{GA}_{3}$ bazı dokularda $\alpha$ ve $\beta$-amilaz gibi hidrolitik enzimlerin sentezini veya aktivitesini arttırarak endospermdeki nişastayı glukoza hidroliz etmekte ve bu sayede embriyonun glukoz ihtiyacinı karşılamakta ve embriyonun büyüme potansiyelini arttırmaktadır (Varner, 1965). Bununla birlikte apikal meristem ve kambiyum aktivitesini arttırarak bazı bitki organlarının büyüme ve gelişimini hızlandırmaktadır (Paleg, 1965). GA3'ün tohum çimlenmesi üzerinde etkili olduğu ayrıca tuzluluk gibi bazı stres koşulları altında çimlenme oranlarında artış sağladığ (Naeem ve Muhammad, 2006; Afzal ve ark., 2005). Bu çalışmada farklı $\mathrm{GA}_{3}$ dozlarının 24 saat süreyle uygulaması sonucunda kontrol gruplarına göre çimlenme oranlarının (kontrol, 50, 100, 200, 400, 800 $\mathrm{mg} / \mathrm{l}$ sirasiyla \% 47.9, 58.3, 56.5, 58.1, 51.4, 32.3) düşük hormon dozlarında arttığı yüksek dozlarda ise azaldığı görülmektedir. En fazla çimlenme oranı 200 mg/l $\mathrm{GA}_{3}$ doz uygulanmasında en düşük çimlenme 
oranının ise $800 \mathrm{mg} / \mathrm{G} \mathrm{GA}_{3}$ doz uygulanmasında elde edilmiştir. Birçok araştırmacı tarafından yapılan çalışmalarda 24 saat süre ile yapılan hormon uygulamasının en etkili sonuçları verdiği görülmüştür. Bununla birlikte $\mathrm{GA}_{3}$ uygulamasinın Penstemon digitalis (cv. Husker Red) (Machado de Mello ve ark., 2009); yer minesi (Verbena bonariensis) (Kornegay and Doubrava, 2006), Susam (Sesamum indicum) (Kyauk ve ark.,1995), Sesleria varia (Casti-glioni ve ark., 2004), Cyclocarya paliurus (Fang ve ark.,2006), ve Galeopsis speciosa (Karlsson ve ark.,2006)' da tohum çimlenmesini etkili bir şekilde arttırdığı rapor edilmiştir. Çalışma sonuçlarına göre, $\mathrm{GA}_{3}$ uygulanan tüm doz gruplarında en yüksek çimlenme oranı 2 yaşındaki anason tohumlarında ve en düşük çimlenme oranı 4 yaşındaki anason tohumlarında izlenmiştir. Tohumun yaşının artması ya da depolama sürecinin artması çimlenme oranını olumsuz yönde etkilemektedir. Bir çok araştırmacı tarafından yapılan çalışmaların sonuçlarına göre, tohumlardaki depolama sürecinin çimlenme gücünün hızlı bir şekilde kaybedilmesine yol açtığ bildirilmiştir (Xia ve ark., 1992; Prasad ve ark., 1996). Ayrıca 1 yaşındaki tohumların 2 yaşındaki tohumlara göre çimlenme oranının düşük olması, aynı yıla ait taze tohumların hasattan hemen sonra kullanılmasından ya da erken hasat yapılmasından dolayı tohumun tam olgunluğa ulaşamamasından kaynaklandığ1 düşünülmektedir. Farklı hormon 50, 100, $200 \mathrm{mg} / \mathrm{l} \quad \mathrm{GA}_{3}$ uygulamasinda ortalama kök uzunluklarının kontrol gruplarına göre daha uzun olduğu görülmektedir. Lesani ve ark. (2011) tarafından yapılan çalışmada $\mathrm{GA}_{3}$ 'ün kök uzamasında etkili olduğu belirtilmekte ve bu çalışmadan elde edilen bulgular ile uygunluk göstermektedir.

\section{SONUÇ}

Tohum yaşı bakımından tohumların fazla bekletilmeden bir sonraki dönem ekiminin yapılmasının uygun olduğu, daha yaşlı tohumlukların kullanılmasının uygun olmadığı söylenebilir. Uygulanan $\mathrm{GA}_{3}$ doz oranlarında ise 50 ve $200 \mathrm{mg} / \mathrm{l}$ arası doz uygulanması çimlenme oranlarında önemli artışlar sağlamıştır. Sonuç olarak Burdur yöresinde ekimi yapılan anason bitkisi tohumlarının çimlenme oranlarının genel olarak düşük olduğu bundan dolayı da daha fazla tohum ekilmek zorunda kalındığını söylemek mümkündür. Anasonda tohumluk olarak kullanılacak yeni çeşitlerin geliştirilmesi ve sertifikalı tohumluk kullanılması gerekmektedir.

\section{KAYNAKLAR}

Afzal I, Shahzad M, Basra A, Iqhbal A 2005. The Effects of Seed Soaking with Plant Growth Regulators on Seedling Vigor of Wheat Under Salinity Stress. Stress Phys. pp. 6-14.

Akgül A, Ayar A 1993. Antioxidant Effects of Turkish Spices. J. Agric. For. 17, 1061-1068.

Başer KHC 1997. Tıbbi ve Aromatik Bitkilerin İlaç ve Alkollü İlaç Sanayilerinde Kullanımı, Anadolu Üniversitesi, T.B.A.M. İstanbul Ticaret Odas1, Yayın No: 39, İstanbul.
Baydar H 2016. Tibbi ve Aromatik Bitkiler Bilimi ve Teknolojisi, Süleyman Demirel Üniversitesi Ziraat Fakültesi 2016-Yayın No:51 5. Bask1 s. 200, Isparta

Bell DT, Rokich DP, Mcchesney CJ, Plummer JA 1995. Effects of Temperature, Light and Gibberellic Acid on the Germination of Seeds of 43 Species Native to Western Australia. J. Vegetat. Sci., 6: 797-806.

Casti-glioni A, Colombo A., and Tosca A 2004. Evaluation of germination capacity and priming techniques in Selsleria varia ,aplant for restoration of calcareous grasslands. 27th International Seed Testing Symposium, Budapest; Hungary; 17-19 May. p. 122

Ceylan A 1996. Medicinal Plants II: Essential Oil Plants. İzmir, Turkey: Ege University Agriculture Faculty Press (in Turkish)

Durmuş E, Yiğit A 1998. Agricultural Areas of Turkey. In: Proceedings of the 4th National Geography Symposium, 25-26 May 2006; Ankara, Turkey: Tücaum, pp. 101-113

Fang, S, J. Wang, Z. Wei, and Z. Zhu 2006. Methods to break seed dormancy in Cyclocarya Paliurus (Batal). Iljinskaja. Scientia Hort. 110: 305-309.

Fincher GB 1989. Molecular and Cellular Biology Association with Endosperm Obilization in Germination Cereal Grains. Ann. Rev. Plant Physiol. Plant Mol. Biol., 40: 305-346.

Gulzar S, Khan MA 2002. Alleviation of salinityinduced dormancy in perennial grasses. Biol. Plant, 45: 617-619

Kara N 2015. Yield, Quality, and Growing Degree Days of Anise (Pimpinella anisum L.) Under Different Agronomic Practices. Turk. J. Agric Forestry. 39:1014-1022.

Karlsson, L.M, J.A.L. Ericsson, and P. Milberg 2006. Seed Dormancy and Germination in the Summer Annual Galeopsis speciosa. Weed Res. 46:353-361.

Kaya N 1990. Batı Anadolu Anason (Pimpinella anisumL.)'larının Bazı Kalite Özellikleri Üzerinde Araştırma. Ege Üniversitesi Ziraat Fakültesi Dergisi, 26, 91-101.

Kornegay, J. and N. Doubrava. 2006. Friends of the J.C. Raulston Arboretum Newsletter. Bul. 10, No. 1. North Carolina State University, Raleigh, NC.

Kyauk H, N.W. Hopper, R.D. Brigham. 1995. Effects of Temperature and Presoaking on Germination, Root Length and Shoot Length of Sesame. Environ. Exp. Bot.35:345-351.

Lessani H, and M. Mojtahedi 2011. Green Plant Life (Gals. Davis Sot.). Tehran Uni. pp: 578.

Liopa-Tsakalidi A, Zakynthinos G, Varzakas T, Xynias IN 2011. Effect of $\mathrm{NaCl}$ and $\mathrm{GA}_{3}$ on Seed Germination and Seedling Growth of Eleven Medicinal and Aromatic Crops. Journal of Medicinal Plants Research. ISSN 1996-0875

Machado de Mello A, Streck N.A, Blankenship E.E, Paparozzi E 2009. Gibberellic Acid Promotes Seed Germination in Penstemon digitalis cv. Husker Red. Hortscience 44(3):870-873. 
Meena SS, MehtaRS, Lal G, Anwer MM 2012. Effect of Agronomic Practices on Productivity and Profitability of Anise. J Spices Aromatic Crop 21: 102-105.

Naeem MA, Muhammud S. 2006. Effect of Seed Priming on Growth of Barley (Hordeum vulgare) by Using Brackish Water in Salt Affected Soils. Pak J Bot. 38:3: 613-622

Paleg, L. E 1965. Physiological Effects of Gibberellins. A. Rev. PI. Physiol.,16,291

Prasad, J.S., Kumar, R., Mishra, M., Kumar, R., Singh, A.K., Prasad, U.S. 1996. Characteristics of litchi Seed Germination. Hortscience, 31: 1187-1189
Ritchie S, Gilroy S. 1998. Gibberellins, Regulatin g Genes and Germination. New Phytol.140: 363-383.

Tunçtürk M, Yıldırım B. 2006. Effect of Seed Rates on Yield and Yield Components of Anise (Pimpinella anisum L.). Indian J Agr Sci 76: 679-681.

Varner J.E 1965. Enzymes. In: Plant Biochemistry (Ed. by J. Bonner and J. E. Vamer), pp. 14-20. Academic Press, London and New York.

Xia Q.H, Chen, R.Z., Fu, J.R. 1992. Effects of Desication, Temperature and Other Factors on the Germination of Lychee and Longan Seeds. Seed Sci. \& Technology. 20: 119-127. 